\title{
Incentivo ao turismo por meio da identificação e mapeamento do Patrimônio Cultural do Distrito do Saí, São Francisco do Sul (SC)
}

\section{Encouraging tourism by identifying and mapping Distrito do Saís Cultural Heritage, São Francisco do Sul (SC)}

André Souza de Lima'

geoandrelima@gmail.com

Cibele Piva Ferrari ${ }^{2}$

cibelpiva@gmail.com

\section{Sandra Paschoal Leite de Camargo Guedes ${ }^{3}$}

sandraplcguedes@gmail.com

\section{Resumo}

O presente artigo buscou, através de um estudo interdisciplinar, envolvendo geografia, história e a teoria das representações sociais, identificar o patrimônio cultural do Distrito do Saí, em São Francisco do Sul (SC), e assim relacionar o potencial turístico da região com a preservação dos bens locais. Foram aplicados 300 questionários e realizadas 18 entrevistas orais com a população do município para a identificação e a análise dessas representações sociais. A partir disso, foram selecionadas 22 unidades patrimoniais de relevante interesse cultural, as quais foram registradas e mapeadas. A pesquisa resultou na confecção de um acervo cartográfico georreferenciado com a identificação dessas unidades, podendo ser utilizado em qualquer Sistema de Informações Geográficas (SIG). O resultado da pesquisa poderá ser utilizado como subsídio à criação de novas ferramentas de gestão, as quais tenham como objetivo a preservação do patrimônio, bem como possibilitem com que a população tenha acesso a esses locais, tendo em vista seu potencial turístico e sua importância histórica.

Palavras-chave: Turismo; Patrimônio Cultural; Representações Sociais; São Francisco do Sul; Distrito do Saí.

\begin{abstract}
This article aimed to, through an interdisciplinary study involving geography, history and theory of social representations, identify the cultural heritage of Saí District (Distrito do Saî), in São Francisco do Sul (SC), and thereby, establish relations between the tourism potential of the region to the preservation of local goods. Were applied 300 questionnaires, and held 18 oral interviews with the local population for the identification and analysis of social representations. From this, 22 equity units of significant cultural interest were selected, recorded and mapped. The research resulted in the production of a georeferenced cartographic collection with the identification of these units that may be used in any geographic information system (GIS) environment. The research results can be used as subsidy to the creation of new management tools which aim to preserve the heritage, as well as enable the population to have access to these places, considering its tourist potential and its historical importance.
\end{abstract}

Keywords: Tourism; Cultural Heritage; Social Representations; São Francisco do Sul; Distrito do Saí.

1 Geógrafo e mestrando no Programa de Pós-Graduação em Geografia, da Universidade Federal de Santa Catarina (UFSC).

2 Historiadora e doutoranda no Programa de Pós-Graduação em Educação, da Universidade do Estado de Santa Catarina (UDESC).

3 Doutora em História, Professora do Departamento de História e do Programa de Mestrado em Patrimônio Cultural e Sociedade, da Universidade da Região de Joinville (Univille). 


\section{Introdução}

O presente artigo buscou, através de um estudo interdisciplinar, envolvendo geografia, história e a teoria das representações sociais, identificar o patrimônio cultural do Distrito do Saí, em São Francisco do Sul (SC), e assim relacionar o potencial turístico da região com a preservação dos bens locais. O estudo foi motivado por inquietações relacionadas a possibilidades teóricas de estudo do patrimônio cultural a partir da visão da população diretamente envolvida, assim como buscou conhecer quais os elementos que ajudaram nessa construção simbólica. Tal identificação se articula com o desenvolvimento de políticas e atividades voltadas para estes interesses, partindo dos desejos da população envolvida. O patrimônio cultural está inserido em um debate sobre valores sociais, sendo que a patrimonialização de um bem perpassa a atribuição de valores, sentidos, usos e significados. Os bens culturais não possuem, por si só, os valores que os transformam em patrimônios culturais, são os indivíduos que lhes atribuem estes valores dentro de um campo de disputas, afirmação e legitimação de identificações, bem como de processos de ativação de memórias. Segundo Sandra Pellegrini (2009), as memórias do passado fundamentam a coesão entre os indivíduos e também são elas que evidenciam as diferenças culturais.

O direito à memória refletida no patrimônio cultural de diversos grupos, está diretamente ligado à formação do indivíduo enquanto cidadão, pois pressupõe o reconhecimento da diversidade e necessidade de convivência entre grupos com características culturais distintas. Uma forma de difundir o acesso e o conhecimento sobre o patrimônio cultural é o turismo e, por meio deste, a educação patrimonial. Esta pode ser compreendida como uma prática social, um processo educativo que busca conduzir os indivíduos em um processo de conhecimento ativo que objetiva a apropriação e a valorização dos bens patrimoniais, por meio do qual esses indivíduos se tornarão agentes na preservação do patrimônio cultural (OLIVEIRA, 2011). O conhecimento a respeito do patrimônio cultural possibilita ao indivíduo compreender o mundo em que está inserido, reforçando a valorização da diversidade cultural brasileira.

A educação patrimonial é "um aspecto chave para o sucesso da política de preservação do patrimônio cultural” (OLIVEIRA, 2011, p. 20). É por meio dela que os indivíduos vão se apropriar do patrimônio cultural e entender a necessidade e a importância de preservá-lo e valorizá-lo. Tornam-se, assim, agentes ativos nesse processo, o que também está relacionado com o fortalecimento dos sentimentos de pertencimento e identificação. Para tanto, as ações pedagógicas relacionadas ao patrimônio cultural por meio do turismo precisam ser orientadas de maneira a tornar o conhecimento um instrumento de preservação, uma ferramenta que aproxime os indivíduos dos bens patrimoniais de forma sensível.

Por outro lado, é reconhecida a grande dificuldade em identificar e localizar o patrimônio cultural, o que não acontece com outros bens municipais legalmente instituídos. O que pode ser considerado patrimônio cultural de um município, estado ou país? Quais os critérios para defini-los? Certamente não basta o registro, é necessário saber o que deve ser registrado, quais os bens que expressam a memória e a identidade da sociedade. Pressupõe-se que a partir da análise das representações sociais e de ferramentas de mapeamento que possibilitem a execução de análises espaciais, como o geoprocessamento, seja possível identificar o que a sociedade considera como seu patrimônio cultural e, assim, instituir políticas de preservação, bem como possibilitar experiências da comunidade junto ao patrimônio histórico e, consequentemente, à sua história.

\section{O patrimônio cultural de São Francisco do Sul (SC)}

São Francisco do Sul é um dos seis municípios banhados pelas águas da baía Babitonga, um sistema estuarino o qual, além da rica biodiversidade, tem importante papel econômico em toda a região devido a sua grande aptidão portuária. Situada no litoral norte de Santa Catarina, a região é formada, também, pelos municípios de Araquari, Balneário Barra do Sul, Garuva, Itapoá e Joinville, assim como pela presença de 24 ilhas. O município de São Francisco do Sul é constituído pela Ilha de mesmo nome, sede do município, por 
outras 24 ilhas e pelo Distrito do Saí, que está localizado na porção continental, separados da sede pela baía Babitonga (Figura 1).

Figura 1 - Localização de São Francisco do Sul, com destaque para o Distrito do Saí.
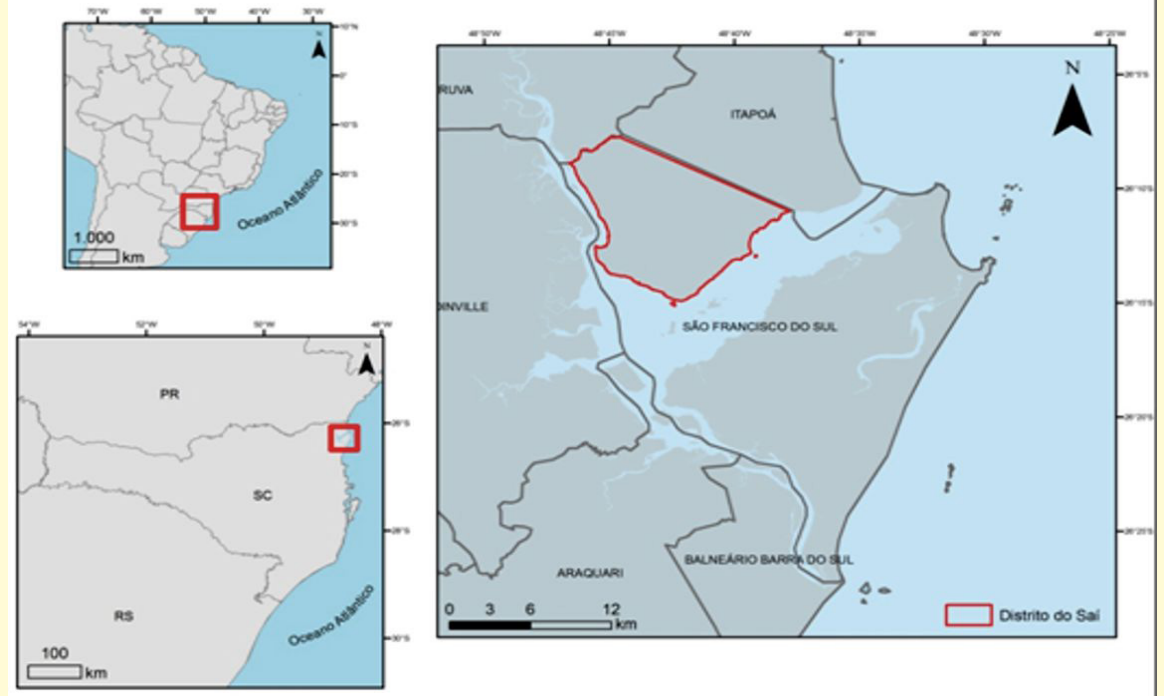

Fonte: André Lima, Grupo de Estudos Interdisciplinares de Patrimônio Cultural/Univille.
A baía Babitonga é considerada a mais importante formação de águas marinhas interiores do litoral norte do estado (BANDEIRA; OLIVEIRA; SANTOS, 2009). Esse complexo estuário abrange uma área de 1.600 quilômetros quadrados, sendo que o mangue que circunda essa área é o maior do estado (VIEIRA, 2008). A cobertura vegetal da região é composta pela Mata Atlânti$\mathrm{ca}$, onde se encontram manguezais e restingas, além da Floresta Ombrófila, os quais formam um rico patrimônio biológico (KNIE, 2002). Na baía, além das ilhas, há lajes expostas, uma extensa rede hidrográfica, inúmeras gamboas e uma rica fauna. Nela vivem mais de 60 espécies de aves, 70 de peixes, bem como crustáceos e moluscos. Raquel S. Thiago (2004, p. 86) destaca que "a baía Babitonga vem promovendo encontros entre homens e culturas através dos séculos", e era denominada pelos antigos como mãe dos pobres, tendo em vista a abundância natural e a produtividade das terras que fizeram dali o principal meio de vida de São Francisco do Sul. As atividades extrativistas têm ainda grande expressão na região e incluem a pesca e a coleta de crustáceos, sendo que a maricultura, com o cultivo de mexilhões e ostras, é algo representativo no estado. A grande extensão da baía abriga também uma intensa atividade náutica, voltada tanto para o turismo quanto para o desporto.

O Distrito do Saí é composto pelas localidades de Vila da Glória, Ilha Alvarenga, Praia Bonita, Estaleiro, Frias, Ramos, Torno dos Pintos, Caeté, Lamin, Ilha da Rita e Saí Mirim, e por duas ilhas: a Ilha da Rita e a Ilha Alvarenga, conforme pode ser visto na Figura 2.

Entre o Distrito do Saí e a sede do município o acesso é realizado por meio de balsa (ferryboat) e

Figura 2 - Localidades do Distrito do Saí.

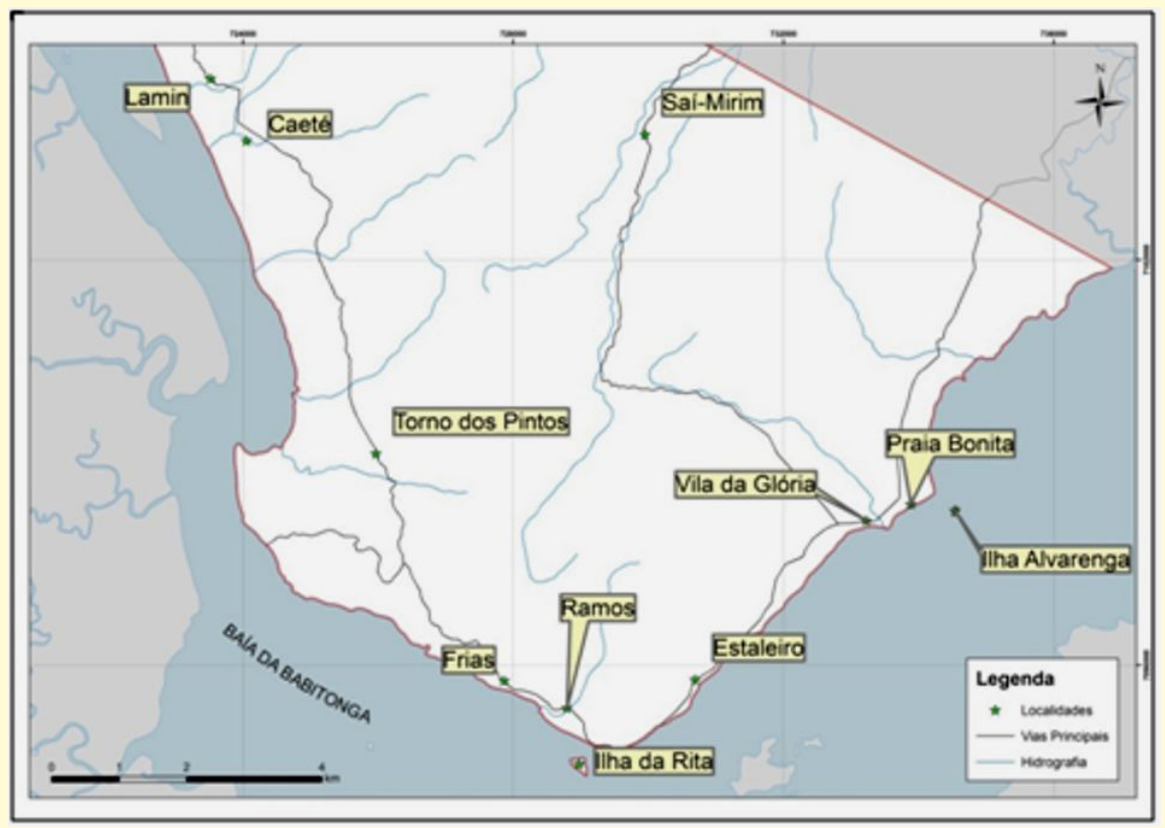

Fonte: André Lima, Grupo de Estudos Interdisciplinares de Patrimônio Cultural/Univille. por pequenas embarcações, ou por rodovias e vias urbanas, destacando-se o acesso principal por meio da Rodovia BR-280, que cruza o canal do Linguado, ao sul da baía Babitonga, atualmente aterrado. Conforme relato dos moradores locais, apesar da distância de aproximadamente quatro quilômetros entre a Ilha de São Francisco do Sul e a área continental do município, a integração da população não é dificultada por problemas de acesso. Além disso, tendo em vista que a população, em sua maioria, tem relação estreita com o mar, o acesso via meios de transporte marítimos é facilitado.

O Porto é a principal fonte econômica do município, que conta 
com a atividade turística em segundo lugar e, em terceiro, a industrial. Algumas indústrias foram atraídas para a região em função do Porto. Segundo dados do IBGE (2011), a população é de cerca de 42.500 habitantes, dos quais 93\% residem na Ilha de São Francisco do Sul. A data de chegada dos primeiros europeus é um assunto polêmico. Existe a hipótese de ser atribuída de forma pioneira à Binot Palmier de Goneville, que comandava uma expedição a bordo do veleiro L'Espoir e que, supostamente, esteve ali em 1504, mas as descrições de viagem não levam à certeza de que a região descoberta se tratava de São Francisco do Sul (PERRONE-MOISÉS, 1992). A historiografia local não ignora essa hipótese, mas atribui a fundação de São Francisco do Sul a Lourenço de Andrade e Luis Rodrigues Cavalinho, que constituíram no local a Vila de Nossa Senhora da Graça do Rio São Francisco Xavier do Sul, em 1658. Apesar da controvérsia, é algo incorporado à representação histórica da cidade, sendo a comemoração da fundação um chamariz turístico: considerando a chegada de Goneville, ela é a terceira cidade mais antiga do país (GUEDES, 2005). Em 2004, quando São Francisco do Sul supostamente completou 500 anos, foram feitos muitos festejos e atividades culturais que deram grande visibilidade à cidade e às questões referentes à história e ao patrimônio.

Certo é, no entanto, que há mais de cinco mil anos já viviam na região os povos sambaquianos, pescadores-coletores-caçadores, que construíam com conchas e areia estruturas de uso múltiplo, posteriormente utilizadas por indígenas carijós e guaranis (OLIVEIRA et al, 2007). Existem registros de mais de 150 desses sítios pré-coloniais no entorno da baía Babitonga - sendo que existem ainda extensas áreas em que não foram desenvolvidas pesquisas - e é possível que sejam encontrados outros (BANDEIRA, 2010). De acordo com Dione Bandeira (2005), há uma grande variedade entre os sambaquis, referente à sua constituição - diferenças de altura e comprimento, por exemplo -, que se relacionam com o tempo de permanência dos sambaquianos no local ou atividades diferentes desenvolvidas pelos grupos. Apesar dessas diferenças, em todos os sambaquis que foram pesquisados, a constituição é de camadas de conchas e de areia sobrepostas, e entre elas encontram-se vestígios da cultura material que indicam que esses eram locais de moradia onde se vivia como em uma aldeia. Segundo a autora, não se sabe qual é o destino desses grupos e são poucos os sambaquis pesquisados porque a destruição por agentes naturais e antrópicos é algo que atinge a muitos deles.

A enorme presença de sítios arqueológicos na região possibilitou que o francisquense tivesse uma convivência muito próxima com esse patrimônio arqueológico nacional, seja por meio do imaginário popular, em inúmeras lendas e mitos que envolvem os sambaquis (SILVA, 2004), ou na utilização indevida das conchas para pavimentação de ruas e canteiros e para a produção da cal, ou mesmo por intervenções do Instituto do Patrimônio Histórico e Artístico Nacional (Iphan) ou de outros pesquisadores em diferentes ocasiões (OLIVEIRA et al, 2007; GUEDES, FINDLAY \& HEINZELMANN, 2004).

Percebe-se porque a região é destacada como "um nicho ecológico muito favorável para a ocupação humana” (SANTOS et al, 2004, p. 13), já que foi, desde milhares de anos, povoada por diversos grupos. Desde o século XVII, os povos nativos tiveram que dar espaço a navegantes estrangeiros que descobriram as condições excepcionais da baía Babitonga quando buscavam por abrigo para descanso, reparos e reabastecimento. Isso porque São Francisco do Sul passou a ser referência nas cartas náuticas a navios portugueses, espanhóis e também de outras nacionalidades, o que fez com que o povoamento se desenvolvesse no local por meio de seu porto natural, à custa da aniquilação dos nativos. A primeira iniciativa colonizadora registrada foi espanhola, mas a vila de Nossa Senhora da Graça do Rio São Francisco Xavier do Sul, fundada em 1658, "se consolidou como uma extensão da conquista portuguesa, que tinha como epicentro a cidadela de São Vicente, no litoral de São Paulo" (SANTOS et al, 2004, p. 13). Além destes, ainda incluem-se na formação étnica de São Francisco do Sul os açorianos vindos de Florianópolis; escravos negros; os franceses, que implantaram o Falanstério do Saí, no Distrito do Saí; e os imigrantes europeus que vieram para as colônias agrícolas da região. Também fazem parte desse contexto as consequências da ocupação de uma das ilhas do arquipélago, a Ilha da Rita, como base naval na ocasião da Segunda Guerra Mundial.

O principal destaque no patrimônio cultural do município é, sem dúvida, o Centro Histórico, tombado desde 1987 em âmbito federal e classificado como sítio histórico urbano nacional (SHUN) de média abrangência. Os cerca de 400 imóveis remontam aos períodos entre 1650 e 1720, 1820 e 1860 e até 1930, sendo que nessa área e no entorno imediato também está localizado o centro cívico e religioso, assim como o principal polo de comércio e prestação de serviços do município (PAULI, 2010). Testemunha de diversos momentos impor- 
tantes, os casarios do Centro Histórico possibilitam que a história seja visualizada no dia a dia dessa população. Muitos dos imóveis já foram alterados, mas a conservação de grande parte é algo que chama a atenção não apenas dos turistas, mas dos pesquisadores que procuram compreender os processos históricos ali desenvolvidos e perceber as relações que a população tem com esse patrimônio, seus usos e significados na contemporaneidade.

A área de proteção delimitada pelo Iphan em 1987, com o objetivo de garantir a integridade dessa paisagem urbana, foi revitalizada entre 2002 e 2012 por meio do Programa Monumenta, uma ação de recuperação sustentável do patrimônio histórico urbano brasileiro sob tutela federal, em que os recursos para que os proprietários restaurassem seus imóveis são originários de um contrato de empréstimo com o Banco Interamericano de Desenvolvimento e o Governo Federal (PAULI, 2010). Neste projeto, obras de conservação e restauro, bem como medidas econômicas, institucionais e educativas, foram desenvolvidas buscando o retorno econômico e social dos investimentos, tendo como objetivo final a sustentabilidade desses bens.

Diante disso, é perceptível no estudo das ações turísticas voltadas ao patrimônio cultural de São Francisco do Sul que elas se voltam, em sua maioria, para o Centro Histórico. O presente artigo pretende apresentar ferramentas para a gestão turística do patrimônio cultural, especificamente por meio do estudo das representações sociais e do geoprocessamento. Acredita-se que sejam ferramentas que possibilitem o acesso ao conhecimento das demandas da população em relação ao seu patrimônio cultural. Partindo, para isso, do exemplo do Distrito do Saí, notadamente uma região deficitária de políticas voltadas para o conhecimento e a difusão do patrimônio cultural desse território.

\section{Patrimônio Cultural e interdisciplinaridade}

Abreu e Chagas (2009, p. 72) defendem que estudar a constituição do patrimônio cultural e a sua relação com a sociedade é um caminho para conhecer a própria sociedade. Sua identificação é necessária para que ele seja incluído nas atividades da gestão municipal, tanto as relacionadas ao fomento da cultura do município, quanto as que envolvem sua inclusão na agenda turística. Os autores afirmam que a cultura serve para a integração das pessoas, inclusive de diferentes países, trazendo benefícios não apenas políticos, mas também econômicos. A salvaguarda do patrimônio não é somente uma obrigação estatal relacionada à preservação da história local, mas algo ligado à vida dos indivíduos em sociedade e que influencia a construção cultural de cada grupo.

Para George Yúdice (2006), a cultura configura-se como um recurso inesgotável que atrai e gera investimentos relacionados ao desenvolvimento econômico e turístico, por exemplo. A cultura na contemporaneidade é, então, um capital a ser negociado, consumido, vendido, experimentado. $\mathrm{O}$ autor afirma que o capitalismo neoliberal se aproxima da redefinição do que é cidadania e da forma de exercê-la, pois a cultura passa a ser reconhecida como um aspecto que deve ser performatizado na ação cotidiana dos indivíduos enquanto cidadãos, e a cultura local é a referência para sua atuação global. O fato da produção de determinados bens estar ligada a aspectos culturais faz com que eles sejam mais desejados. A dinamização das identidades e das representações, também reguladas a partir desse processo, segundo Yúdice, estão intimamente ligadas à constituição do patrimônio cultural com o contexto em que cada indivíduo está inserido, assim como à forma como ele se relaciona com isso.

Salvadori (2008) afirma que o patrimônio serve como suporte da memória, capaz de produzir identificações a partir do modo como os indivíduos se apropriam da realidade histórica que os cerca e das relações sociais que ocorrem no espaço. Sandra Pellegrini (2009, p. 23) concorda com a importância que o patrimônio em si, bem como as memórias que carrega, têm para a formação de identidades, afirmando que os bens culturais tomados como legados recebidos do passado, vivenciados no presente e transmitidos às gerações futuras, reúnem "referenciais identitários, memórias e histórias — suportes preciosos para a formação do cidadão".

Dessa forma, o patrimônio cultural pode ser traduzido nas manifestações materiais e imateriais de uma coletividade, abrangendo os bens simbólicos de todos os grupos, sendo que os bens preservados devem estar à disposição e usufruto de todos (CANCLINI, 2008). O patrimônio é um campo onde conflitam interesses, influenciando diretamente o cotidiano dos indivíduos: 
As memórias e referências do passado fundamentam, por um lado, a coesão entre os indivíduos que compartilham afetos, sensibilidades, tradições e histórias. E, por outro, evidenciam diferenças culturais que podem favorecer a aceitação da diversidade como valor essencial para o indivíduo em sociedade (PELLEGRINI, 2009, p. 23).

Para Françoise Choay (2006), o patrimônio cultural expressa as identidades e as memórias de uma sociedade e contribui para mantê-las e preservá-las, daí a noção de que sejam referentes à nação, ao grupo e à comunidade, sendo a materialização do que deve ser transmitido às gerações futuras, expressão da história de um povo. Resultante de relações sociais, o patrimônio é sempre fruto de escolhas, de quem tem o poder de optar pela memória e a identidade dignas de serem preservadas e difundidas. O campo do patrimônio cultural é, de fato, complexo, e nele diversos interesses e formas de interpretação convivem e conflitam.

Diante disto, pode-se compreender o patrimônio cultural como resultado de escolhas das práticas culturais representadas na materialidade e na imaterialidade de uma sociedade que merecem ser preservadas e difundidas, sendo que essas escolhas são fruto de disputas e jogos de poder. Para estudá-lo, deve se levar em conta o que significa dentro do contexto em que está sendo analisado e como se constituem as lutas políticas e sociais em torno dele, que são produtos das representações sociais construídas em determinado momento e local a respeito do próprio patrimônio cultural. Por estar relacionado a aspectos não apenas históricos, mas também geográficos, econômicos, sociais e psicológicos, entre outros, considera-se que o estudo do patrimônio cultural é interdisciplinar por essência. Seus estudos devem levar em conta essa multiplicidade de aspectos que existem nas relações estabelecidas entre o local, a população e os usos deste patrimônio, bem como as referências materiais e imateriais advindas disto. A Teoria das Representações Sociais, desenvolvida por Serge Moscovici dentro da Psicologia Social na década de 1960, possibilita que seja compreendido como a sociedade se apropria do seu patrimônio cultural, contribuindo para seu estudo e orientando decisões a respeito de sua gestão.

\section{Representações sociais e Patrimônio cultural}

Para Moscovici (2009, p.40), as representações sociais refletem a maneira como os indivíduos pensam, agem e procuram compreender o sentido de suas ações e pensamentos, e "todas as interações humanas, surjam elas entre duas pessoas ou entre dois grupos, pressupõem representações. Na realidade, é isso que as caracteriza". 'Têm como funções, segundo o autor, convencionalizar os objetos, descrever, classificar e explicar a realidade. E dessas funções se desdobram outras: comunicação, orientação e justificação de comportamentos, identificação e integração do novo, equilîbrio cognitivo e social, bem como de normativa das relações intergrupais (RODRÍGUEZ, 2004).

É grande a diversidade de estudos e formas de aplicação da Teoria das Representações Sociais, sendo esta uma possibilidade para a pesquisa dos fenômenos sociais e psicossociais em conjunto com outras disciplinas. Essa teoria propõe uma visão global das relações e do comportamento dos indivíduos, o que contribui para uma maior compreensão da realidade e ação sobre a mesma. Explica os processos relacionados à criação de conceitos básicos como sentido comum, vida cotidiana e linguagens, mostrando como se organiza o pensamento que culmina em uma determinada representação que é compartilhada por um determinado grupo social.

Desde sua criação, a Teoria das Representações Sociais tem alcançado grande importância na Psicologia Social e seu campo de estudos tem crescido consideravelmente. Rodríguez (2004) destaca que novas perspectivas teóricas e metodológicas enriqueceram o estudo dos processos de construção social da realidade, sendo este um marco explicativo dos fenômenos psicossociais complexos e variados em contextos culturais heterogêneos. A Teoria das Representações Sociais propõe uma abordagem metodológica plural na pesquisa do pensamento do senso comum, privilegiando o social e o objeto do estudo (RODRÍGUEZ, 2004), configurando-se como uma importante forma de estudar o pensamento social e seus mecanismos de forma ampla. Para Moscovici (2009), além de refletir o comportamento e a estrutura social, uma representação também condiciona ou responde a isso, isto é, se deve não apenas a uma origem coletiva, mas a um objeto coletivo e, por este motivo, é compartilhada por todos e reforçada pelas tradições.

Dessa forma, trata-se de uma teoria que, associada a outras ciências, contribui sobremaneira para o estudo do patrimônio cultural, pois é no senso comum que se formam as representações que o constituem enquanto um bem. E é na orientação das atividades relacionadas ao patrimônio cultural que reside a contribuição deste estudo das representações sociais e da utilização do geoprocessamento como ferramenta de apoio. 


\section{Geoprocessamento: gestão e planejamento do patrimônio cultural}

O geoprocessamento é uma ferramenta, dentre as diversas disponíveis e conhecidas, que integra os Sistemas de Informação Geográfica (SIG). Possui caráter transdisciplinar e é utilizado em diversas áreas do conhecimento, pelos mais distintos profissionais, para análises espaciais e confecção de mapas temáticos que possibilitam identificar as demandas e as potencialidades específicas a cada problema. As técnicas utilizadas são descritas por Ferreira et al (2011) como ferramentas de integração de tecnologias, em que a aquisição de informações e o seu tratamento posterior a transformam. Desta maneira, os dados cartográficos utilizados na elaboração de mapas, juntamente com os dados alfanuméricos, se tornam informações geográficas.

Dentre as diversas aplicações para o uso do geoprocessamento, destaca-se o planejamento e gestão do território, sobretudo do espaço urbano. A utilização de mapas para conhecer a infraestrutura disponível para a população e assim identificar áreas carentes da atenção pública é cada vez mais comum. Essa atenção voltada para a área urbana, principalmente, é regida por leis que regulamentam e estabelecem diretrizes gerais da política urbana na constituição federal, como, por exemplo, a Lei Federal no 10.257/2001, conhecida por criar uma ferramenta básica que norteia e estabelece metas a fim de desenvolver o espaço urbano, o Plano Diretor. Entretanto, conforme Lei Municipal no $763 / 1981$, apenas uma pequena fração do território continental do município de São Francisco do Sul, onde se localiza o Distrito do Saí, é classificada como área urbana.

Diante do exposto, é fato que existem instrumentos legais que possibilitam a gestão do território; entretanto, a proposta é o emprego de novos meios e técnicas para que a gestão considere nas suas políticas relacionadas ao patrimônio cultural a totalidade do território do município. O conhecimento da demanda a partir das representações da população e o geoprocessamento dos dados analisados podem ser utilizados pela gestão para potencializar o desenvolvimento de políticas turísticas voltadas ao patrimônio cultural de todo o território do município.

O Iphan também estabelece normas para a gestão e o planejamento do espaço urbano através de uma série de leis, dentre as quais pode-se destacar a Lei n 6.766, de 19 de dezembro de 1979, que dispõe sobre o parcelamento do solo urbano:

\footnotetext{
Art. $13^{\circ}$ Caberão aos Estados o exame e a anuência prévia para aprovação, pelos Municípios, de loteamento e desmembramento nas seguintes condições:

I - Quando localizados em áreas de interesse especial, tais como as de proteção aos mananciais ou patrimônio cultural, histórico, paisagístico e arqueológico, assim definidas por legislação estadual ou federal (BRASIL, 1979).
}

Segundo Moura (2003), a utilização do geoprocessamento na gestão do patrimônio cultural permite à gestão pública ter uma visão holística da realidade e de maneira didática e muito ágil. A autora afirma que, a partir do momento que se tem as informações espacializadas, é possível gerir e monitorar, com rigidez, possíveis intervenções no patrimônio do município. Além disso, pode-se identificar as potencialidades da estrutura do patrimônio a fim de explorá-lo turisticamente, incrementando, assim, a receita do município e da população local.

O conhecimento da região através de dados históricos, das representações sociais e do geoprocessamento dessas informações, constitui importante ferramenta para a gestão do seu patrimônio cultural. A identificação do patrimônio cultural reconhecido pela população possibilita que a gestão municipal amplie a sua área de atuação, revendo as prioridades de investimento e fomento cultural. O turismo cultural encontra, na existência desses bens, uma forma de sustentabilidade do seu patrimônio cultural por meio de sua exploração como recurso turístico. A preservação do patrimônio cultural e sua difusão por meio do turismo favorecem também que "a sociedade tenha mais oportunidades de conhecer a si própria" (FUNARI \& PINSKY, 2009, p. 17). Os recursos advindos com consumo cultural, por um lado, e a manutenção da qualidade de vida por meio do acesso à memória, por outro, justificam o uso turístico do patrimônio cultural e fundamentam a sua proteção e preservação.

O turismo cultural não deve ser associado ao turismo tradicional ou "de massa". Contudo, cabe ressaltar que o turismo por si só está diretamente ligado à cultura de maneira geral. Conforme Mancini (2007), o turismo cultural não necessariamente remete a algo material, pois envolve, sobretudo, a maneira como se vê. Ou seja, é algo que deve ser vivenciado, ultrapassando o modelo tradicional contemplativo do turismo, pois 
Dossiê

exige contato com a população e, em alguns casos, instrução prévia, como em Distrito do Saí, onde muitas das edificações históricas podem passar despercebidas.

Da mesma maneira que o turismo cultural possui uma série de peculiaridades, ele é destinado a um público bastante restrito, pois geralmente não dispõe de estrutura adequada, nem ao menos sinalização. Como ressalta Mancini (2007), as características descritas, ao mesmo tempo em que não atraem um grande número de turistas, garantem a autenticidade do local. Em contrapartida, caso o local receba um grande número de pessoas e não possua estrutura para atendimento ao turista, poderá sofrer uma série de impactos, sobretudo negativos. Para o autor, o turismo, em geral nos últimos anos, deixou de ser considerado exclusivamente uma atividade comercial e passou a estar intrinsecamente relacionado à sociedade. Não obstante, tem a possibilidade de integrar planos de preservação. Para o caso do Distrito do Saí, o turismo não é incentivado e ao mesmo tempo não existem políticas públicas de preservação associadas ao patrimônio cultural da região.

\section{O Patrimônio Cultural do Distrito do Saí}

$\mathrm{Na}$ Ilha de São Francisco do Sul há um vasto patrimônio cultural reconhecido, composto pelo Centro Histórico, que é a maior representação de seu patrimônio e o que potencializa a identidade coletiva (SILVA, 2010). Para além desse patrimônio que é composto por casarios, remanescentes da ocupação luso brasileira dos séculos XVIII e XIX, existe, ainda, muito a ser conhecido e identificado, principalmente na porção continental do município, a qual ainda carece de atenção do poder executivo do município, ao que se refere a políticas de preservação do patrimônio cultural. A identificação desse patrimônio permitirá que ele seja incluído nas atividades da gestão municipal, tanto relacionadas ao fomento das manifestações culturais do município quanto na sua inclusão na agenda turística.

Para viabilizar o trabalho de mapeamento e catalogação do patrimônio cultural do Distrito do Saí, foi necessário o reconhecimento da região com base em registros oriundos de pesquisas pretéritas e de informações públicas do município de São Francisco do Sul. Além disso, foi utilizado o diagnóstico arqueológico da região realizado pelas arqueólogas Maria Cristina Alves e Francine Cristina Martins (2006), que identifica todos os sambaquis da região, entre outras diversas unidades patrimoniais, bem como a pesquisa realizada por Fernanda Mara Borba (2012), que identificou e analisou sítios históricos na região.

A pesquisa de campo, composta por entrevistas estruturadas e não estruturadas, foi iniciada após aprovação e adequação às normas do Comitê de Ética na Pesquisa da Universidade da Região de Joinville - Univille. As entrevistas orais foram doadas ao Laboratório de História Oral da Univille, onde estão à disposição do público.

As entrevistas estruturadas foram realizadas a partir da aplicação de 300 formulários ${ }^{4}$, sendo 150 homens e 150 mulheres e cuja quantidade corresponde a 0,7\% da população do município, segundo dados do IBGE (2011). Os sujeitos foram divididos em três faixas etárias: 1) 18 a 29 anos; 2) 30 a 55 anos; 3) acima de 56 anos. Os formulários foram aplicados a moradores do Distrito do Saí, nos principais pontos de concentração da população, como em estabelecimentos comerciais e nas ruas principais, assim como em casas próximas a essas vias.

O enunciado das perguntas foi apresentado aos entrevistados e as respostas registradas pelos pesquisadores conforme os níveis pré-definidos na confecção do formulário a partir da revisão bibliográfica. Os dados foram tabulados com auxílio da ferramenta de survey, do Google Docs ${ }^{5}$, e exportados para o software Excel, para que pudessem ser analisados. Devido à abrangência da pesquisa, para elaboração do presente artigo apenas uma das questões do formulário foi utilizada, ou seja, a que indagava sobre o que o entrevistado considerava como patrimônio cultural do Distrito do Saí e onde estava localizado.

Os resultados obtidos nessa questão foram comparados e identificados com aqueles obtidos em 18 entrevistas $^{6}$ não estruturadas que seguiram a metodologia da história oral (MEIHY, 1996; FERREIRA \& AMADO, 1998). A escolha dessas pessoas foi feita por meio de uma rede de informantes obtida durante a pesquisa (MEIHY, 1996)

4 Os formulários eram compostos por 28 questões abertas e fechadas.

5 A palavra refere-se ao método de pesquisa quantitativo e é uma das ferramentas das quais dispõem os usuários do Google. Possibilita que o formulário seja alimentado virtualmente e posteriormente estes dados sejam exportados ao Excel para tratamento e análise.

6 O número de 18 entrevistas correspondeu a seis pessoas (três de cada sexo) para cada faixa etária entrevistada na pesquisa estruturada, numero considerado suficiente pela exaustão de informações conseguidas durante as primeiras entrevistas (MEIHY, 1996). 
e constituída por sujeitos-chave que poderiam fornecer informações mais detalhadas sobre o patrimônio cultural existente na localidade. Dentre os dezoito sujeitos entrevistados, estavam ex-secretários municipais, professores e ex-fuzileiros navais, além de pessoas que nasceram ou moram na localidade há muito tempo.

É importante salientar que os resultados encontrados, apesar de parecerem, à primeira vista, apenas quantitativos, permitiram inferir a relação da população com seu patrimônio cultural e perceber o que era considerado ou não patrimônio para as pessoas entrevistadas, ou seja, suas representações sobre o patrimônio cultural existente. A falta de precisão nas respostas, que não permitia saber a localização do bem citado e, muitas vezes, nem mesmo a que ruína as pessoas estavam se reportando, foi suprida com um trabalho de identificação in loco por meio de pesquisa de campo. Assim, a partir das informações obtidas por meio dos formulários e das entrevistas orais, todo o Distrito do Saí foi percorrido pelos pesquisadores com a utilização de mapas e de um receptor GPS. Todas as principais vias foram visitadas, bem como grande parte das vias secundárias e foram identificados 22 pontos de interesse cultural que coincidiam com o que havia sido mencionado nas entrevistas.

Os resultados da pesquisa mostraram que o patrimônio cultural do Distrito do Saí é diverso. Dentre os 22 pontos, existem ruínas relativas à ocupação nos séculos XVII e XVIII, bem como engenhos e igrejas. O patrimônio imaterial citado está relacionado às práticas e conhecimentos locais, tais como o modo de fazer a farinha de mandioca, a construção de canoas, a pesca artesanal, entre outros. Esse patrimônio é disperso e pouco conhecido, mas lembrado pela população.

Figura 3 - Localização da Ilha da Rita.

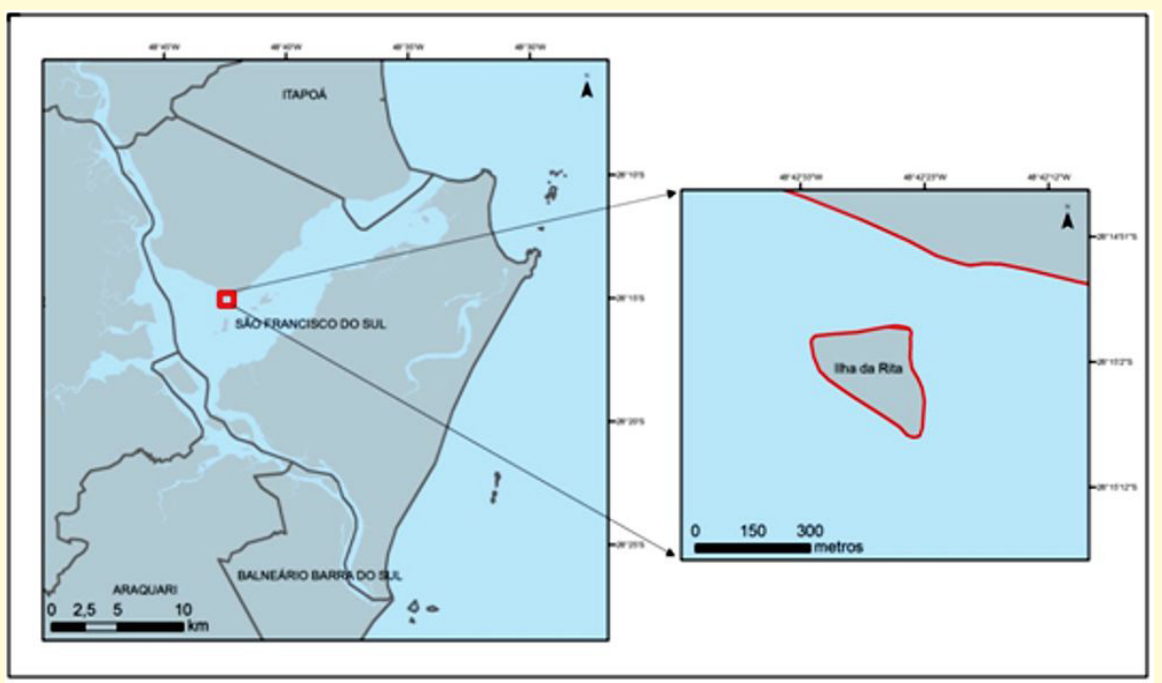

Fonte: André Lima, Grupo de Estudos Interdisciplinares de Patrimônio Cultural/Univille.

Figura 4 - Localização do Patrimônio cultural no Distrito do Saí.

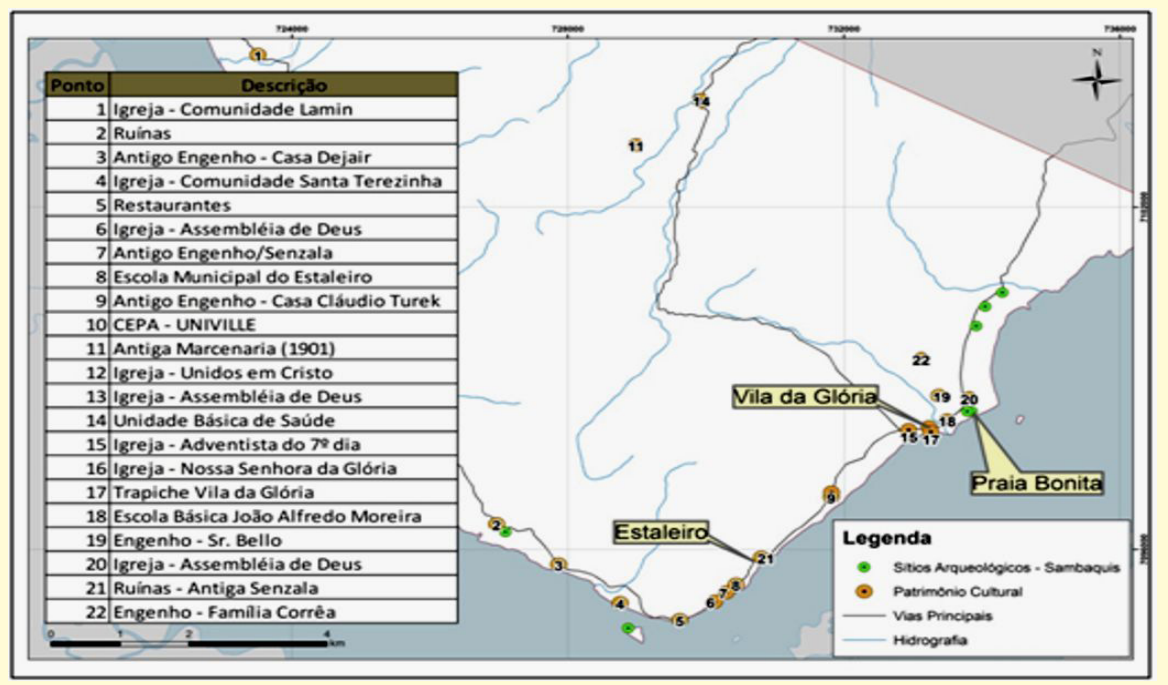

Fonte: André Lima, Grupo de Estudos Interdisciplinares de Patrimônio Cultural/Univille.
Um dos locais evidenciados como patrimônio cultural da região pelos entrevistados está localizado a 200 metros do Distrito do Saí, a Ilha da Rita (Figura 3) que tem relevância não apenas local como também nacional. Durante a $2^{\mathrm{a}}$ Guerra Mundial foi utilizada como base naval, servindo de ponto de abastecimento de água potável, carvão e óleo aos navios. Todos os 300 entrevistados por meio do formulário tinham conhecimento da Ilha da Rita, mas apenas 33\% a conhecem pessoalmente. Entre os entrevistados que já foram à Ilha, 69\% são moradores do Distrito do Saí, que estão bem mais próximos do local. Um dado que reflete a situação contemporânea da Ilha é que, desses 33\% que já a visitaram, $90 \%$ têm mais de 30 anos. Como a Ilha está fechada para visitação desde 1999, é natural que os entrevistados mais novos não tenham tido a oportunidade de conhecê-la, apesar de terem ciência sobre sua história, que faz parte do currículo escolar, ou por ouvir dela falarem os amigos, familiares e a população local.

O resultado do trabalho de campo possibilitou a espacialização de todas as coordenadas obtidas, através de pontos em mapas temáticos, a fim de conhecer a localidade onde se en- 
contram cada um dos pontos obtidos. Com a localização dos 22 pontos, foi possível observar que a Vila da Glória e o Estaleiro possuem um maior número de unidades de patrimônio cultural reconhecidos pela população, e a região da Praia Bonita concentra um maior número de ocorrências de sambaquis, conforme pode ser visto na Figura 4.

\section{Considerações finais}

Objetivou-se identificar e analisar as representações sociais da população de São Francisco do Sul sobre o patrimônio cultural do Distrito do Saí. A partir do estudo dessas representações sociais, foi possível identificar junto à população os espaços patrimoniais reconhecidos por estes indivíduos, bem como investigar as memórias e representações a eles ligadas. Dessa forma, foi possível perceber a rede de relações que a população local estabelece com o patrimônio cultural.

Os mapas elaborados, e a base cartográfica preparada, poderão ser utilizados em consultas de viabilidade para implantação de novos empreendimentos, assim como para a criação de unidades de preservação municipal. Dada a versatilidade dos SIG's, a mesma metodologia adotada para o mapeamento do Patrimônio Cultural do Distrito do Saí poderá ser aplicada em outros setores da prefeitura, ou utilizada por municípios vizinhos.

Destaca-se que o estudo das representações sociais, auxiliado pelo geoprocessamento, são eficientes recursos para a gestão do patrimônio cultural. A partir da pesquisa realizada para a identificação espacial deste patrimônio, foi possível conhecer melhor a relação da população com estes bens e desenvolver as potencialidades dos mesmos em relação à comunidade local e também para fins turísticos. Estas informações podem também orientar a elaboração de políticas públicas direcionadas às potencialidades destacadas para a preservação do mesmo, bem como a integração de todo o patrimônio cultural do município, respeitando as diversidades existentes.

A proteção do patrimônio cultural nos municípios está, em partes, prevista em lei, mas, na maioria das vezes, o desconhecimento do que seja patrimônio cultural e/ou onde ele se localiza são empecilhos à sua proteção. Cabe ao poder executivo do município conhecer onde está localizado o seu patrimônio cultural, tarefa bastante árdua e que requer metodologia adequada. Para isso, a partir da pesquisa desenvolvida sugerem-se três etapas que foram necessárias para realização do presente estudo: 1) Conhecimento e identificação: compreensão do conceito de patrimônio cultural a fim de identificá-lo a partir das representações sociais; 2) Registro e mapeamento: após a identificação do patrimônio cultural municipal, é necessário registrá-lo, catalogá-lo e por fim manter atualizado um banco de dados geográfico com informações pertinentes à sua localização; 3) Gestão: a criação de políticas públicas que tenham como objetivo a preservação do patrimônio, e que possibilitem que a população tenha acesso a esses locais, tendo em vista seu potencial turístico e sua importância histórica.

Em relação ao Distrito do Saí, esta pesquisa demonstrou que o geoprocessamento pode ser utilizado em regiões em que o Patrimônio Cultural ainda é desconhecido pela municipalidade. Localizado fora do Centro Histórico tombado, este patrimônio é pouco conhecido, e através das metodologias empregadas na análise das representações sociais, foi possível identificar quais são as unidades reconhecidas pela população e registrá-las. A partir deste reconhecimento social do patrimônio cultural do Distrito do Saí e identificação geográfica do mesmo, é possível favorecer sua gestão por meio de medidas que visem sua preservação, seja via processos de tombamento ou registro, ou pelo desenvolvimento de atividades relacionadas à educação patrimonial e ao turismo, fomentando a cultura e também a sustentabilidade local.

Por fim, cabe ainda ressaltar a complexidade e a relevância do estudo interdisciplinar do patrimônio cultural, buscando compreender os diversos aspectos relacionados à sua constituição e seu reconhecimento pela sociedade. Este que pode ser impulsionado por meio da atividade turística, utilizada como incentivo e valorização o patrimônio cultural. Turismo e patrimônio cultural se relacionam intimamente com a qualidade de vida e são questões que têm permeado mais recorrentemente as agendas públicas e demandando pesquisas para desenvolvimento dessa relação. Estima-se que as proposições do presente artigo inspirem novas discussões e reverberem em ações que considerem a demanda da população e a gestão turística do patrimônio cultural dos municípios de forma ampla. 


\section{Referências}

ABREU, Regina; CHAGAS, Mário (Orgs.). Memória e patrimônio: ensaios contemporâneos. 2. ed. Rio de Janeiro: Lamparina, 2009.

ALVES, Maria Cristina; MARTINS, Francine Cristina. Obras de Pavimentação Asfáltica de Estradas Municipais em Joinville e São Francisco do Sul. Joinville: OAP, 2006.

BANDEIRA, Dione da Rocha. Povos sambaquianos: os construtores de montes de conchas e os mais antigos moradores da Baía Babitonga. Revista Joinville Ontem e Hoje. Joinville: Câmara Municipal de Joinville, p. 4-9, mar. 2005.

. Sambaquianos: os mais antigos habitantes da Baía da Babitonga. In: JOINVILLE. Prefeitura Municipal. . Joinville: os primeiros habitantes. Itajaí: Editora Casa Aberta, 2010.

BANDEIRA, Dione da Rocha; OLIVEIRA, Eloy L.; SANTOS, Adriana Maria P. Estudo estratigráfico do perfil nordeste do Sambaqui Cubatão I, Joinville/SC. Revista do Museu de Arqueologia e Etnologia, São Paulo, p. 1-23, 2009.

BRASIL. Lei no 10.257 de 10 de julho de 2001. Regulamenta os Arts. 182 e 183 da Constituição Federal, estabelece diretrizes gerais da política urbana e dá outras providências. Diário Oficial [da] República Federativa do Brasil, Brasília. Disponível em: < http://www.planalto.gov.br/ccivil_03/leis/LEIS_2001/L10257.htm>.

Acesso em: 14 dez.2012.

Lei no 6.766 de 19 de dezembro de 1979. Dispõe sobre o parcelamento do Solo e dá outras providências.

Diário Oficial [da] República Federativa do Brasil, Brasília. Disponível em: $<$ http://www.planalto.gov.br/ccivil 03/leis/ LEIS 2001/L10257.htm>.

Acesso em: 14 dez.2012.

BORBA, Fernanda. Arqueologia da Escravidão numa Vila Litorânea: Vestígios Negros nas Fazendas Oitocentistas de São Francisco do Sul (Santa Catarina). 2013. Dissertação (Mestrado em Patrimônio Cultural e Sociedade) - Universidade da Região de Joinville, Joinville. 2013.

CANCLINI, Néstor García. Culturas Híbridas: Estratégias para entrar e sair da modernidade. 4. ed. São Paulo: Edusp, 2008.

CARVALHO, Fernanda Ricalde Teixeira. Turismo e patrimônio cultural material. Cultur: Revista de Cultura e Turismo, Ilhéus, ano 9, n. 1, p. 143-159, out. 2014.

CHOAY, Françoise. A alegoria do patrimônio. 3. ed. São Paulo: Ed. Unesp, 2006.

ArcGIS Desktop: software. Versão 10. Redlands, 2010. Disponível em < http://www.esri.com/software/arcgis/arcgis-for-desktop>. Acesso em: 7 jul. 2015.

FERREIRA, Fernanda Costa et al. O Papel do Geoprocessamento na preservação do Patrimônio Cultural nacional nos municípios de Porto Seguro e Santa Cruz Cabrália, Bahia: procedimentos e desafios. In: SIMPÓSIO BRASILEIRO DE SENSORIAMENTO REMOTO, 15, 2011, Curitiba: Anais... INPE, 2011. p. 4102-4109.

FERREIRA, Marieta de Moraes; AMADO, Janaina (Orgs.). Usos \& Abusos da História Oral. 2. ed. Rio de Janeiro: Fundação Getúlio Vargas, 1998.

FUNARI, P.P.A.; PINSKY, J. (Orgs.). Turismo e patrimônio cultural. 4 ed. São Paulo: Contexto, 2009.

GUEDES, Sandra. P. L. C.; FINDLAY, Eleide A. G.; HEINZELMANN, Marta. R. Representações Sociais sobre o patrimônio histórico e pré-colonial dos municípios de Araquari, São Francisco do Sul e Balneário Barra do Sul pertencentes à Baia da Babitonga. Revista Univille, Joinville, v. 9, p. 96-105, 2004.

GUEDES, Sandra. P. L. C. A construção do herói. In: REUNIÃO ANUAL DA SBPH, 24, 2005, Curitiba. Anais..., 2005. p. 285-290.

IBGE. Censo 2010. Rio de Janeiro: IBGE, 2011. 
Dossiê

KNIE, Joachim L.W. (Coord.) Atlas Ambiental da Região de Joinville - Complexo Hídrico da Baía da Babitonga. Florianópolis: FATMA/GTZ, 2002.

MANCINI, Lorena Angélica. Turismo Cultural: Proposta de roteiro interpretativo para o município de São Francisco do Sul - SC. 2007. 202 fls. Dissertação (Mestrado em Turismo e Hotelaria) - Universidade do Vale do Itajaí, Balneário Camboriú. 2007.

MARINHO, Ana Paula Lima. Metodologia para integração dos dados do Patrimônio Histórico aos dados da Informação Básica para Edificações utilizando técnicas de geoprocessamento. 2008. Monografia (Especialização em Geoprocessamento) - Universidade Federal de Minas Gerais, Belo Horizonte. 2008.

MEIHY, José Carlos Sebe Bom. Manual de História Oral. 5. ed. São Paulo: Loyola, 1996.

MOSCOVICI, Serge. Representações Sociais: Investigações em Psicologia Social. 6. ed. Petrópolis: Vozes, 2009.

MOURA, Ana Clara M. Geoprocessamento aplicado ao planejamento urbano e à gestão do patrimônio histórico de Ouro Preto-MG. In: CONGRESSO BRASILEIRO DE CARTOGRAFIA, 21, 2003, Rio de Janeiro. Anais... Rio de Janeiro: Sociedade Brasileira de Cartografia, 2003. p. 1-9.

OLIVEIRA, Cléo Alves Pinto. Educaşão Patrimonial no Iphan. 2011. 141 f. Trabalho de Conclusão de Curso (Especialização em Gestão Pública) - Escola Nacional de Administração Pública, Brasília. 2011.

OLIVEIRA, Fabiano A. et al. Projeto Atlas Histórico da Região da Baía da Babitonga. In: CONGRESSO BRASILEIRO DE CARTOGRAFIA, 23, 2007. Anais... Rio de Janeiro, 2007. p. 2258-2264.

PAULI, Roberta Cristina Silva. Representaçoes sociais sobre o centro histórico tombado de São Francisco do Sul. 2010. Dissertação (Mestrado em Patrimônio Cultural e Sociedade) - Universidade da Região de Joinville, Joinville, 2010.

PELLEGRINI, S. C. A. Patrimônio cultural: consciência e preservação. São Paulo: Brasiliense, 2009.

PERRONE-MOISÉS, Leyla. Vinte Luas. Viagem de Paulmier de Gonneville ao Brasil: 1503-1505. São Paulo: Cia das Letras, 1992.

RODRÍGUEZ, Eulogio Romero (Org.). Representaciones sociales: atisbos, cabilaciones del devenir de cuatro décadas. México: Benemérita Universidad Autónoma de Puebla, 2004.

SALVADORI, M. A. B. História, ensino e patrimônio. Araraquara: Junqueira \& Marin, 2008.

SANTOS, Silvio Coelho; NACKE, Anelise; REIS, Maria José (Orgs.). São Francisco do Sul: muito além da viagem de Gonneville. Florianópolis: UFSC, 2004.

SÃO FRANCISCO DO SUL. Prefeitura Municipal. Lei ñ 763/1981. Lei de Uso e Ocupação do Solo. Disponível em: <http://www.leismunicipais.com.br/a/sc/s/sao-francisco-do-sul/lei-ordinaria/1981/76/763/lei-ordinaria-n-763-1981-dispoe-sobre-o-zoneamento-do-municipio-de-sao-francisco-do-sul-estado-de-santa-catarina-e-revoga-a-lei-n-600-76-2007-12-20.html>. Acesso em: 10 maio 2013.

SILVA, Angela Cristina. Histórias e lendas de São Francisco do Sul. São Francisco do Sul: Letrad'água, 2004.

SILVA, Roberta Cristina. Representações sociais sobre o centro bistórico tombado de São Francisco do Sul. 2010.125 p. Dissertação (Mestrado em Patrimônio Cultural e Sociedade) - Universidade da Região de Joinville, Joinville. 2010.

THIAGO, R. S.; COELHO, I. A Univille na história da paisagem da Ilha da Rita. Revista Univille, Joinville, v. 6, n. 2, p. 49-62, 2001.

YÚDICE, George. A conveniência da cultura: usos da cultura na era global. Belo Horizonte: Editora UFMG, 2006.

VIEIRA, Celso Voos et al. Caracterização morfosedimentar e setorização do complexo estuarino Baía da Babitonga/SC. Boletim Paranaense de Geociências, Curitiba, n. 62-63, p. 85-105, 2008. 